\title{
A Society of Immigrants
}

The Materials Research Society is a "melting pot" and a "rainbow of diversity," reflecting the country in which we are headquartered. We have "immigrated" from "home" disciplines that include computation, electrical engineering, mechanical engineering, chemical engineering, physics, chemistry, and biology. We are also blessed with "native-born" materials scientists and engineers, "native" referring to subject area, not geography. I am an "immigrant" myself, with much of my formal education centered on organic and biological chemistry. Many of our governing members, key committee members, award recipients, and featured speakers are "immigrants," or at least frequent "visitors," as well. The people who run our meetings, the central activity of MRS, are often chosen precisely because of the circuitous route that they took into materials research.

What drives so many of us to "immigrate"? The most probable reason is that it is more fun and productive to collaborate across scientific fields in the course of our work than to be confined to one discipline. We find new colleagues, customers, audiences, and friends in new fields, and discover that the common ground we share is in the realm of materials research. Hence, a materials research "society" evolves, though many of us cannot say that we really started here. We welcome "immigrants" with open arms, conferring instant citizenship (and even encouraging "dual citizenship" with many other professional societies) the moment they arrive at our meeting registration desks. Our constitution is much more lenient than that of the United States, which states that certain office-holders must be at least some number of years old, and that the president cannot, in fact, be an immigrant.

Still, in some ways, we would be a stronger Society, and materials science and engineering would enjoy enhanced vitality, if we did more to encourage "home-bred" members, or at least "immigrants" of a younger age. We would be nurturing a particularly cohesive group whose long-term presence could lead to

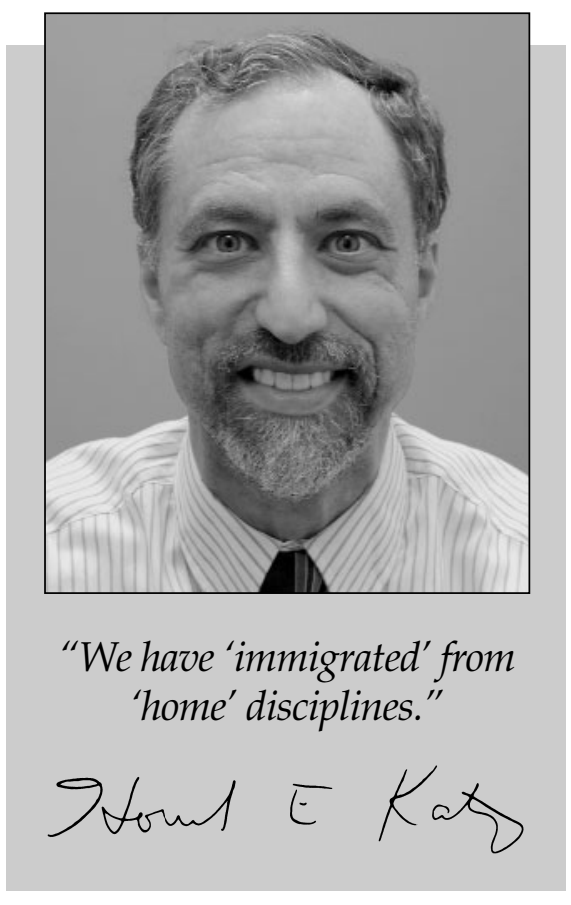

greater credibility with government lobbying associations and political allies, as specific interpersonal interactions were cultivated. A more sustainable educational outreach and support program for materials departments, led by people who themselves went through such departments or who have a high-priority interest in their well-being, could be maintained. Ways to increase the number of such "materials-centric" members include insertion of more identifiably materialsoriented curricula, publications, and even competitions into high schools and offering materials-related course options to meet early college science requirements. Quite a few university centers have begun outreach activities and curriculum development with these aims in mind, and these efforts should be nurtured, sustained, and expanded.

Workshops for science teachers and summer camps for students are held where materials science is explored as a vital and accessible component of the physical sciences, and where activities are developed that lead to richer classroom experiences. Laboratory modules based on materials transformations are being constructed and made available as means of hands-on demonstrations of scientific phenomena, where the students' senses, in addition to their imaginations, are engaged. Delegations from the U.S. National Science Foundation and other externally funded centers bring the excitement of "magical" materials directly into classrooms. In the United Kingdom, efforts are under way to increase science teachers' awareness of materials aspects of the existing A-level (high school) science requirements, and even to begin teaching an explicit course on materials for advanced science students. Just as it is easier to learn a new language from an early age, one's comfort level in a scientific field is often stronger when the immersion begins as a youngster, and positive impressions are made in a multisensory way.

MRS University Chapters provide an excellent early-stage college-level entrée into the materials fields. We were proud to welcome and induct our newest student chapters at the plenary session of the 2003 MRS Fall Meeting, those of Drexel University and the University of Nevada, Reno. They joined the 30 student chapters in universities across the United States.

Another debut that we are proud to announce is the MRS Strange Matter exhibit, a traveling interactive materials science exhibit through which users enter the fascinating, practical, occasionally bizarre, and often beautiful world of materials science through over a dozen hands-on experiences. It is accompanied by a dynamic and interactive Web site at www.strangematterexhibit.com. The traveling exhibit is scheduled for the Liberty Science Center in New Jersey this winter. It is fitting that this "society of immigrants" launches its flagship exhibition within sight of Ellis Island in New York Harbor, where so many "immigrants" in the geographical sense got their start.

HOWARD E. KATZ 2004 MRS President

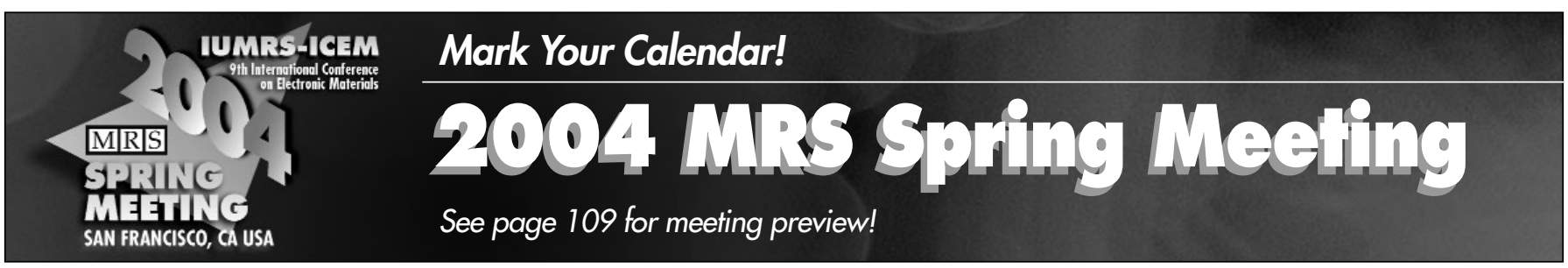

